\title{
Chapter 8 \\ Industry Divide: The Interdependence of Traditional Cinematic Distribution and VOD in Poland
}

\author{
Marcin Adamczak
}

\subsection{Introduction}

This chapter examines interrelations between traditional cinematic distribution and the relatively new field of video on demand (VOD) distribution in Poland. The market logic behind the approach of local cinema distributors to this new phenomenon requires some elaboration. Historically, new modes of movie distribution such as terrestrial, satellite, cable TV, VHS and DVD were sooner or later incorporated into the traditional business model of the film industry, concentrated around cinemas as the primary market and treated as additional sources of revenues. VOD seems to be a challenging technology to incorporate because of its distinct operational logic and a new set of corporate players that are no less powerful than traditional film market behemoths. The chapter is based on seven semi-structured interviews with Polish cinema distributors and managers of VOD services and on statistical market data. It outlines the structure of the VOD market and the differences between this new field and traditional cinematic distribution, interrelations between sectors, power plays between both sides and the impact of the VOD market - perceived by theatrical distributors as an opportunity for additional revenue and as a competitor at the same time. The influence of particular business actors in the VOD sector on traditional distribution will also be examined.

\footnotetext{
M. Adamczak ( $\varangle)$

Department of Anthropology and Cultural Studies, Adam Mickiewicz University in Poznań, ul. Szamarzewskiego 89a, 60568 Poznań, Poland

e-mail: m_adamczak80@wp.pl 


\subsection{Structure of the Polish Market and Interdependence of Industries}

Polish cinema cannot be clearly defined as "small" or "big." The number of annual productions is relatively low, with just over 50 feature films made every year. However, from 2016 onward, the Polish cinema market has been among the top 20 world markets in terms of US dollar-denominated revenue and has been steadily on the rise for the past couple of years. The most accurate description of the Polish market would be to say that it is on the move, undergoing a transformation from a "small" to at least a middle-sized market (Table 8.1).

The market transition process is undoubtedly shaping the relationship between traditional cinematic distribution and the VOD sector in Poland. There are two factors at play - the development of Internet distribution and the VOD market as well as the dynamic development of the traditional cinematic distribution market, which is now the largest in history in terms of box office. Both are interconnected, and significantly growing box office revenues have an impact on the VOD market.

Cinematic distribution allows distributors to make profits or, in some less fortunate situations, at least to cover the print and advertising (P\&A) costs and open up a further possibility of selling television rights, which is still a lucrative business, especially in Pay TV (Pay TV contracts are oftentimes higher than the distributor's net profit from cinematic distribution). In contrast, the once-profitable DVD/Blu-ray market

Table 8.1 Development of the Polish cinema market compared to the five biggest markets in Western Europe and the two biggest markets in Central and Eastern Europe (box office and tickets per capita sold, 2010-2017)

\begin{tabular}{l|l|l|l|l|l|l|l|l}
\hline & France & Germany & UK & Italy & Spain & $\begin{array}{l}\text { Czech } \\
\text { Republic }\end{array}$ & Hungary & Poland \\
\hline $\begin{array}{l}\text { Box office, } \\
\begin{array}{l}\text { 2010 } \\
\text { (admissions } \\
\text { in millions) }\end{array}\end{array}$ & 206.3 & 126.6 & 169.2 & 123.4 & 101.6 & 13.5 & 11 & 37.5 \\
\hline $\begin{array}{l}\text { Tickets per } \\
\text { capita, } \\
2010\end{array}$ & 3.28 & 1.55 & 2.72 & 2.05 & 2.21 & 1.3 & 1.1 & 0.98 \\
\hline $\begin{array}{l}\text { Box office, } \\
\begin{array}{l}\text { 2017 } \\
\text { (millions of } \\
\text { admissions) }\end{array}\end{array}$ & 209.4 & 122.3 & 170.6 & 99.2 & 100.2 & 15.2 & 14.9 & 56.6 \\
\hline $\begin{array}{l}\text { Tickets per } \\
\text { capita, } \\
\text { 2017 }\end{array}$ & 3.1 & 1.5 & 2.6 & 1.6 & 2.2 & 1.4 & 1.5 & 1.5 \\
\hline $\begin{array}{l}\text { Growth in } \\
\text { percent (\%) }\end{array}$ & +1.5 & -3.3 & +0.8 & -19 & -1.3 & +12 & +35 & +51 \\
\hline
\end{tabular}

Source calculations based on Focus: World Film Market reports 
has become so unappealing that in the case of many smaller titles, the distributors are not even particularly inclined to release their film on such media.

For big cinema distributors, the VOD market remains a fairly "technical" sphere treated as an additional source of income-not particularly profitable for now, although this could change in the future (that is why they secure long-term rights to this release window). However, no particular effort is directed in Poland at VOD in terms of intense or innovative promotion. For big distributors such as Kino Świat, Monolith or the subsidiaries of Hollywood studios, the real profit lies in the traditional market (cinema and subsequent television rights), while small- and middle-sized distributors such as Gutek Film carry out a sort of art house vertical and horizontal integration (cinematic distribution, controlling at least a few cinemas, organizing film festivals and controlling their budget for licenses, educational programs financed from public funds). Additionally, large stakeholders among distributors know not only that traditional cinematic distribution offers them the biggest and quickest profits, which is crucial for the company's cash flow, but also that success in this field is the basis for creating an attractive catalogue and gaining a good position in negotiations with VOD services (Table 8.2).

It is particularly telling that apart from Monolith (its Cineman service-www. cineman.pl-has a fairly marginal reach), no distributor has ever even tried to set up their own VOD portal, nor have there been any plans to create a joint platform for several distributors. Kino Świat previously had shares in Strefa VOD and Iplex and is currently distributing its films on YouTube in the AVOD mode. There are, however, a few cases of vertical integration by a distribution company and a large cinema network. Examples include the ITI Group (ITI Cinema-cinematic distribution, Multikino-network of cinemas, TVN and its theme channels-TV station),

Table 8.2 Market shares of Polish distributors, 2013-2017 (in percent)

\begin{tabular}{l|l|l|l|l|l}
\hline Company & 2013 & 2014 & 2015 & 2016 & 2017 \\
\hline UIP & 16.98 & 12.11 & 24.11 & 18.19 & 25.84 \\
\hline Kino Świat & 13.57 & 18.16 & 15.20 & 19.69 & 19.24 \\
\hline Disney & 12.59 & 8.13 & 13.74 & 14.88 & 13.69 \\
\hline Forum Film & 12.49 & 10.50 & 10.07 & 4.98 & 1.33 \\
\hline Monolith & 11.04 & 14.49 & 8.55 & 11.03 & 10.68 \\
\hline Imperial Cinepix & 8.41 & 10.01 & 10.38 & 12.41 & 6.56 \\
\hline Warner & 7.75 & 6.91 & 5.57 & 8.25 & 9.28 \\
\hline Next Film & 3.87 & 6.88 & 4.73 & 1.53 & 5.97 \\
\hline Vue Movie & 8.35 & 6.88 & 1.45 & 3.02 & - \\
\hline Best Film & 1.26 & - & 1.04 & - & - \\
\hline Gutek Film & 1.1 & 1.72 & 1.63 & 1.12 & 1.25 \\
\hline Interfilm & - & 2.09 & 1.68 & 2.17 & - \\
\hline
\end{tabular}

Source calculations based on reports of the Polish Film Institute; the data includes all companies with more than one percent of market share 
Agora (Next Film and its Helios network of cinemas) and an integration of the distribution company Forum Film with the Cinema City network. The VOD market comes across as a quite different and separate entity.

\subsection{The VOD Market in Poland: Concentration Around the Powerful}

The VOD market is characterized by high barriers to entry for new or smaller platforms. The most important is the amount of financial capital needed to acquire comprehensive, fresh and attractive content for the catalogue and to cover the advertising and technological requirements, in addition to the process of operating a portal. Even if smaller players find a niche (e.g., documentary films) or a specialization (e.g., older titles still in demand), they still have to prepare digital files - a costly endeavor, which is not eagerly subsidized by the Polish Film Institute, even though it does support promoting the Polish audiovisual culture abroad. Jan Mogilnicki from Torus Films, a company specializing in the VOD distribution of Polish documentaries, including older titles, points out:

In 2014, we were close to introducing our films to big, global platforms, such as Hulu or iTunes. Then, to my surprise, it turned out that neither we, nor the producers had proper digital materials. Preparing subtitles and screening material for the whole bunch of films is a significant expense. I'm still working on it, step by step (interview, 3 August 2018).

The bankruptcy or closure of independent (Iplex) or smaller (Kinoplex) local companies, even if they were pioneers with initial advantages in the market, and the withdrawal of medium-sized international players (Showmax) indicates that the VOD market is becoming an increasingly concentrated sphere, controlled by global behemoths (Netflix and HBO GO) or local branches of media corporations (player.pl and ipla.tv). Traditional cinematic distribution, on the other hand, is a more open space due to digitalization, which decreased the cost of preparing screening copies. Distributors have a lot of freedom in their purchasing choices, allowing for the existence of smaller players and for the curatorial practices of intermediaries, such as special screenings and a fairly active network of art house cinemas.

The biggest entities of the Polish VOD market are currently: VoD.pl, player.pl, cda.pl, TVP VOD, ipla.tv and WP Pilot, as well as Netflix and HBO GO (Showmax left the market in 2018). A classification of the major VOD providers in terms of ownership shows the structure of the market and differences in comparison to traditional cinematic distribution players and their business roots. The major VOD providers are owned by four types of entities:

- Internet portals (parts of larger media corporations): VoD.pl and WP Pilot

- Powerful TV broadcasters: player.pl, ipla.tv and TVP VOD

- Big international companies with a global reach: Netflix, HBO GO and ncplusgo.com

- Former pirate site on the way toward legalization: cda.pl. 
Table 8.3 Leading VOD platforms in Poland (October 2017-October 2018)

\begin{tabular}{l|l|l|l|l}
\hline \multirow{2}{*}{ Domain } & \multicolumn{3}{|l|}{ October 2017 } & October 2018 \\
\cline { 2 - 5 } & Users & Range (\%) & Users & Range (\%) \\
\hline vod.pl & $4,066,682$ & 14.81 & $3,791,192$ & 13.64 \\
\hline player.pl & $3,609,619$ & 13.14 & $3,218,020$ & 11.58 \\
\hline cda.pl-premium & $2,931,623$ & 10.67 & $3,107,222$ & 11.18 \\
\hline vod.tvp.pl & $2,560,870$ & 9.32 & $2,606,523$ & 9.38 \\
\hline netflix.com & $1,208,480$ & 4.40 & $1,986,895$ & 7.15 \\
\hline ipla.tv & $2,185,550$ & 7.96 & $1,781,479$ & 6.41 \\
\hline wp.pl-pilot & 826,170 & 3.01 & $1,393,499$ & 5.01 \\
\hline showmax.com & 969,068 & 3.53 & $1,269,447$ & 4.57 \\
\hline hbogo.com & 522,294 & 1.90 & 739,336 & 2.66 \\
\hline ncplusgo.com & 309,786 & 1.13 & 383,948 & 1.38 \\
\hline
\end{tabular}

Source Gemius/PBI for wirtualnemedia.p)

Furthermore, TVOD services are also offered by mobile networks-T-Mobile, Orange, Plus and Play, the last being the most active player in the field. Its Play Now service aggregates content from different content providers, actively participates in television markets and buys content independently from the producers. Zuzanna Pawłowska, an expert from the VOD sector (currently working for TVP VOD, who previously collaborated with Iplex and VoD.pl), says: "It's hard to name a platform which would be completely independent. Iplex was one and we all know how it ended up" (interview, 19 November 2018) (Table 8.3).

The visibly strong position of VOD services connected with Polish television channels (Player.pl, Ipla.tv and TVP VOD) is the result of their successful strategy of combining Hollywood blockbusters with popular local television formats (series, talk shows, social and political commentary). As a result, their catalogue is diverse and attractive. Rather than focus on the domestic market, their strong position seems to stem mostly from the wide offer of television programs available on VOD. This gives the online services connected with large television broadcasters an advantage and sets the dichotomous structure of the market, dominated by two types of entities-services linked to the broadcasters and international corporate content providers with a large reach. The market position of the former is the result of the fact that a large portion of the content is produced beforehand by the TV station for its own channels, while VOD is only an extension of TV distribution for the previously created content. Onet and WP are also among the portals with their own VOD services producing original content. However, television stations have much larger content resources. Zuzanna Pawłowska observes that a large portion of her job at the public service broadcaster is convincing other departments that VOD is not cannibalizing television and that the VOD and terrestrial broadcasting are not taking away viewers from each other, but instead both gain by copromoting content on the two platforms simultaneously or by coordinating release times. 
It could be argued that the attitude of the cinematic distributors toward VOD (the aforementioned mixture of disdain and fear) shows that they are mistaken in not paying enough attention to this prospective form of distribution, and therefore are not leveraging it to the fullest. Indeed, it would seem that one of the side effects of the dynamic development of cinema exhibition is a certain conservative attitude of the Polish distribution market. However, statistics concerning the traditional cinematic distribution market and VOD services reveal a more complex picture than it might be initially assumed.

First of all, the Polish VOD market is quite well developed. The $48 \%$ market growth observed in the 2015-2016 European Audiovisual Observatory report seems fairly unimpressive compared to the growth in other countries during the same time period-the Czech Republic (226\%), Croatia (197\%) or Bulgaria (137\%) (Grece and Fontaine 2017: 14). However, the authors of the report point to the fact that the growth was much more intensive in countries where the market had previously been less saturated with VOD services. The Polish market, with its $11 \%$ penetration, was comparable to many western countries, such as Italy (9\%), France (10\%), Belgium $(11 \%)$ and Spain (13\%), and was far ahead of the growth leaders in the first comparison-the Czech Republic, Croatia and Bulgaria (each with 2\% penetration) (Grece and Fontaine 2017: 13). It is also worth noticing that Poland's penetration was far lower than in European countries with the highest VOD penetration-Scandinavia and the UK (Norway 53\%, Sweden 31\%, Finland 28\%, the UK 43\%). Moreover, Poland was the country with Netflix's lowest market share in Europe (only 16\%), which reflects the strength of the portal's local competition (Grece and Fontaine 2017: 24).

It should also be noted that due to the size of the population, the general number of subscribers is currently high. According to Rzeczpospolita, in October 2018, Netflix reached 760,000 individual subscribers. The VOD sector's revenue in Poland in 2016 was estimated at $€ 56.2$ million, which constituted $6.5 \%$ of the British market revenue (€804 million) and $10 \%$ of German market revenue (€540 million), while the cinema market in Poland at the same time was estimated at $14 \%$ of the British market volume and $21 \%$ of the German market volume. The full US dollar-denominated box office in Poland 2016 was \$245 million, compared to British \$1.66 billion and German $\$ 1.13$ billion (Kanzler and Talavera 2017).

Therefore, the VOD market in Poland is less developed than the cinema market when comparing the gap between Polish markets and the most advanced Western markets. At the same time, SVOD revenue in Poland was ten times higher than in the Czech Republic and 25 times higher than in Hungary (while the potential consumer base in both countries is only four times smaller, and the per capita GDP is slightly higher in Hungary and much higher in the Czech Republic) (Grece and Fontaine 2017: 15-16). Thus, the Polish VOD market is quite well developed in the regional context of Central and Eastern Europe. It is very competitive, and it has recently been shaped by two major events-Showmax's withdrawal from the market and attempts by the previously pirate portal cda.pl to legalize its content and become a publicly traded entity. 
Showmax, an international player controlled by Naspers, operating out of South Africa, entered the Polish market in February 2017. From the very beginning it stood out from the crowd with its showy promotional campaigns (widely commented upon promotional videos made by renowned filmmakers-Wojciech Smarzowski and Patryk Vega) and its focus on local content, including a satirical political Web series Ucho prezesa, the well-received series Rojst and the SNL Polska format. In December 2018, the platform announced its withdrawal from Poland. The failure of Showmax demonstrates that in such a dichotomous market, divided between VOD services linked to local TV stations, big Internet portals and global players, it is not enough to be a relatively strong international entity. You have to be a powerful global player with significant financial resources that can be invested in content production and marketing (e.g., companies like Netflix, HBO and Canal+). The VOD market seems particularly difficult for online services without the backing of TV stations or a global reach, even despite their dynamic promotion and the attractive, original content they produce.

The only entity breaking out of the dichotomous structure of the market is cda.pl. It is an interesting case of a pirate platform trying to legalize its operation in the hope of going public and raising capital for further expansion. CDA, which has existed for over a decade, introduced a paid premium SVOD service and shares a portion of its profits with distributors. CDA offers a sizable catalogue, whose volume can be appreciated through a comparison with Netflix's offer for Polish viewers. Netflix offers 2100 films and 800 series for the equivalent of $€ 8.50$ per month. CDA offers 4700 films (although the video quality of the files is usually lower) for the equivalent of $€ 5$ a month. The portal wants to be listed on NewConnect, a part of the Warsaw Stock Exchange, to raise capital for the expansion of its legal content (increasing the number of films with license fees and developing a SmartTV app). NewConnect is intended mostly for companies with a relatively low capitalization, operating in the sector of new technologies, and is less regulated than the standard stock exchange. To this end, CDA boasts about its good relationships with the distributors, not only due to the speed of their notice and takedown procedure (and emphasizing that the illegal content is uploaded by the users), but also thanks to a direct takedown tool available for distributors collaborating with the platform. CDA also reports that in 2018 it handed over PLN 6 million in license fees to the distributors it worked with and stresses the dynamic increase in the number of subscribers.

According to the platform, in November 2018, they had 155,000 active subscribers (compared to 100,000 in early 2018 and 47,000 in early 2017). CDA also reports that its profit for 2018 is the equivalent of US \$1 million net. Yet at the same time, the portal was featured on the MPAA list of notorious pirate sites, and its mode of action is a source of controversy for the industry. One of the Polish VOD market players said anonymously:

I've heard the distributors working with them are satisfied. They're getting some money out of it and they control whether their content is published - that's also crucial. But generally, the VOD market and foreign entities are distrustful of the platform. I think building your position on an illegal platform and entering the market saying: "We have this many viewers, 
we can pay the distributors, and we have the people we can sell films to", seems rather unfair (interview, 6 August 2018).

The case of CDA is a clear-cut example of how the only way to survive in a difficult, competitive market for an entity which is not a part of the dichotomous system is capital accumulation (let us not forget about the downfall of the pioneering Iplex, the closing of Kinoplex and the retreat of Showmax), drawing on its initial position based on piracy and profiting from the distribution of content without paying the rightsholders. In other words, to base the development on unpaid, illegally obtained content. An anonymous market observer accurately noted that only the accumulation of financial capital in the gray zone of piracy and, first and foremost, the accumulation of the viewer base in the same way can lead to legalizing the operations of such a platform. Obtaining a wide base of free content seems to be the only development option other than gaining backing from a TV station or being a global player with a budget and potential customer base significantly bigger than that of the competition.

\subsection{The Separation of Cinema Distribution and the VOD Market}

The size of the SVOD market in Poland in 2016 was about $25 \%$ the size of the cinema market revenue (Grece and Fontaine 2017; Kanzler and Talavera 2017). The volume for 2016 was $€ 56.2$ million, while the combined revenue from cinemas was $€ 217.5$ million. It is a significant amount, especially if we treat is as a potential new source of revenue.

However, the interviews reveal that the VOD sector offers very low fees to cinema distributors, the rightsholders for online fields of exploitation. An anonymous distributor reveals: "Iplex paid 0.25 zloty per view and went bankrupt. Ipla pays $0.2-0.3$ zloty per view, but initially it used to pay a little more. Kinoplex paid 0.5 zloty per view. And I need to further split this amount 50/50 with the producer" (interview, 6 August 2018).

It is a very low level of income for distributors compared to revenues from cinemas and television. Meanwhile, the net profit for the Polish distributors from one cinema ticket sold, after splitting the revenue with the cinema owner, is around 7-8 zloty, over 200 times more than from VOD proceeds. The profit is reduced due to the producer taking its share, which is usually $50-80 \%$ of the amount received after splitting the profits with the cinema, but first the distributor deducts its P\&A costs from the revenue.

Moreover, the VOD market in Poland has shown a strong tendency to concentrate around the strongest players. Even though the traditional cinematic distribution market is also dominated by the biggest players, such as the distribution agencies of Hollywood studios, companies in business with the "Big Six" and other entities with access to the biggest local commercial hits, the market still leaves a lot of room 
for smaller distributors. Hollywood studios sell their films based on long-term general contracts, in TVOD and SVOD packages of films from the studio library as well as new, premiere titles. VOD services leave much less room for smaller entities and the degree of market concentration around the biggest players is significantly higher. There are no small VOD companies hiring a few employees and successfully distributing fewer mainstream titles.

The fees paid by VOD operators to outside rightsholders is an indicator that any future growth of the market and its revenue stream will most likely be consumed by entities other than cinema distributors-corporations owning TV stations and producing in-house content, further distributed via the VOD portals they control. The exception is the corporate Hollywood "Big Six" studios. However, they stopped using the local distributors as middlemen for the selling of VOD licenses, and therefore operate somehow beyond the local context through their European branches. Nowadays, Disney and Warner have their own Polish distribution agencies. United International Pictures is the sole rightsholder for the films of Universal, Paramount and Sony, and the fate of Imperial Cinepix (the Polish distributor of Twentieth Century Fox) is uncertain, as its content provider has been taken over by Disney.

The functioning of the VOD sector is connected to the advantage of scaling. According to Pawłowska, contracts for SVODs are usually signed for 100 titles or $50 \mathrm{~h}$ of programming delivered every quarter, for example for two years, not for a small selection of five titles. Smaller deals do happen, but the pragmatic factor of a similar amount of time devoted to a small contract (for a few titles) and a big contract (around 100 titles) usually rules in favor of the latter.

Furthermore, since 2018 there has been a noticeable change in the approach of cinema distributors to the VOD market. Thus far, one of the only conditions they insisted on was the sequential opening of distribution windows and a shortened, but nevertheless long, hold-back period for cinematic distribution-blocking the availability of the film in other distribution channels for four months after its premiere. Only the smaller distributors were open to negotiations in this matter, but these revolved around shortening the hold-back period, not its elimination. The question remained whether people would actually not go to see a film in the cinema if they had the alternative of watching it at the same time in the comfort of their home-on Pay TV or a VOD platform. This is a crucial issue for the future of the interdependence and relations between the traditional cinematic market and VOD and the whole system of hold-backs which was the cornerstone of the distribution market's structure. At least a partial answer could be obtained by experiments with suspending hold-backs.

The first two such experiments related to distributing content produced by Netflix were made on the Polish market recently. In the autumn of 2018, Monolith distributed Paul Greengrass' 22 July at the time of its Netflix premiere. In December 2018, a similar move was made by Gutek Film distributing Netflix's famed production Roma by Alfonso Cuarón. In an interesting twist, the film was distributed by the very same company whose board member and main buyer, Jakub Duszyński, in an interview conducted just a year before had expressed the absolute importance of opening distribution windows sequentially. At the moment, a more flexible approach 
and attitude of openness on the part of at least some cinema distributors may be observed and they are partly testing out a suspension of window sequencing.

And yet, the circumstances surrounding the distribution of the two films, regardless of which company distributed them, were rather unusual and thought-provoking. A viewer not familiar with the film market could easily miss the seemingly unimportant detail that the distributors' logos did not appear before the screenings. Only Netflix's logo was displayed. It was also rather difficult to find information about the distributors of the films online. In the case of 22 July and Monolith, it may even be that the earlier information about the theatrical distributor was, for some reason, removed, and - as nothing can be completely erased from the Internet - there were only some traces left: a trailer taken down from YouTube, a note in the repertoire of one of the cinemas, and a piece of information on the Twitter account of a film fan (Kozłowsky 2018; Twitter 2018).

What is more, we do not know the box office results of the films, since the distributors - two serious, seasoned companies - did not report them to boxoffice.pl, a members-only portal for film professionals, the main tool for any distributor and market analyst. As a result, only Netflix has the data necessary to analyze the impact of the lack of sequencing of distribution windows on the box office results of a given title. It seems reasonable to assume that the "hidden" details behind distribution of the films and the lack of box office data are the results of contracts signed between distributors and Netflix. We do not know the conditions under which Monolith and Gutek Films agreed to distribute the American portal's content (e.g., their share of the profits). Nevertheless, it may be supposed that the terms were not particularly favorable to the distributors, who were clearly the weaker partners in this relationship. Netflix's tactics of restricting the industry's access to distribution data seem to be part of an aggressive corporate strategy, an informal "war" the portal wields against other film market entities. The portal's possessiveness does not inspire confidence in the future of the relationship. Local distributors were treated as subcontractors of secondary importance who offered the service of contacting cinemas and convincing them to screen the film, and there appears to be a visible tendency by Netflix to push them into anonymity. In some way, the theatrical distribution was also part of a marketing campaign for a parallel release of these titles on VOD in a day-to-date model.

However, it should be noted here that Amazon Studios takes a different approach. It has worked with various distributors in the Polish market, including Kino Świat, Gutek Film and M2Films, with titles such as Handmaiden (2016, directed by Park Chan-wook), Manchester by the Sea (2017, directed by Kenneth Lonergan), Paterson (2017, directed by Jim Jarmusch), Suspiria (2018, directed by Luca Guadagnino) and Beautiful Boy (2019, directed by Felix Van Groeningen). At no time has Amazon "covered up" the local distributor, nor has it concealed the film's box office results.

Nevertheless, in the new power structure, especially if Netflix's approach prevails, the key powerful players of traditional cinema, such as the distributors, will likely become increasingly marginalized, pushed into the position of second-rate subcontractors, with their role limited to that of unnecessary middlemen or even eliminated. This sheds new light on the defensive approach of the distributors toward the new 
forms of distribution. The distributors are well aware of the importance of relationships with cinema owners and programmers, with journalists and the media, and of the value of knowledge about the preferences and habits of the audiences in the local context. These factors, at least to some extent, promote the national players, turning them into typical intermediaries, so crucial in the modern culture of content (over)abundance. The unique knowledge, contacts and the function of intermediaries allow even small local distributors to survive the confrontation with bigger international players although their budgets for licenses and promotion are minuscule compared to the global behemoths (obviously this means surviving in a market niche).

\subsection{Conclusions}

The traditional cinematic distribution and VOD markets in Poland are characterized by a much larger degree of separation and independence than one might suspect. The two markets are ruled by different logics and, most important, controlled by different entities with different revenue streams, which rarely overlap. The entities active in the cinema distribution sector and in the VOD sector almost never actively operate in the parallel market as players, not just as rights vendors or content providers. The VOD sector is much closer to the television sector than to traditional cinematic distribution. It is linked not only on the level of corporate management (those VOD services with the backing of powerful television broadcasters who control them), but also on the level of content, which is delivered by broadcasters. According to Pawłowska, TV formats such as series, talk shows and journalistic programs are the most popular formats among Polish VOD users. What can be seen here is the hybridization of content when an Internet platform produces content in TV formats or when TV content is a very popular part of its offer. In this way one can notice the "second life" of television on the Internet.

The revenue stream is more tightly controlled by the entities dominating the VOD market, acting mostly in the interest of their own and their superior corporate structures, unwilling to share it with outside content providers. Therefore, the traditional cinematic market players-distributors and, indirectly, producers-are largely cut off from the stream of VOD revenue and are looking for alternative development models. These include both traditional vertical integration and a modified approach: a distribution company with its own festival, which allows it to control the license budget of the festival (and practically sell its own films to itself), thus reducing the risk of buying expensive licenses. At the same time, traditional cinematic distribution in Poland has experienced constant and dynamic growth in recent years. Hence, one may expect that it will remain partially separated from the VOD market.

Furthermore, there were interesting experiments with simultaneous distribution of content on VOD portals and in cinemas without the hold-back periods (the examples of 22 July and Roma). However, in those cases, cinema distributors were hired 
as subcontractors to perform the service of introducing the film to cinemas. The subcontractor remained a mostly anonymous entity and was certainly not treated as an equal partner. It can be assumed that if such arrangements come to characterize the business, the position of the distributor will be much weaker, and if the experiments prove lucrative, the content provider could easily set up its own cinematic distribution department, supported by large advertising budgets. After a period of building up contacts and gathering experience, the need for an outside cinematic distribution provider would be eliminated. Establishing a direct line between consumer and filmmaker and the elimination or marginalization of intermediaries-independent distributors and producers-will clearly benefit VOD services.

The Polish VOD market is more concentrated around the most powerful players and has much higher barriers to entry than the traditional cinematic distribution market. The barriers are also much higher than is generally assumed based on the image of the Internet as a particularly open medium, stemming from the popular start-up mythology of the IT sector. In reality, it is the traditional cinematic market that turns out to be more freewheeling and open to smaller and new local players. It is less controlled by the biggest corporate players than the VOD services.

The distributors recognize the limitations of Polish cinema-the language barrier, a modest number of productions with fairly low budgets, and the export opportunities limited to the Polish diaspora abroad and the art house sector (after gaining the symbolic capital of awards at respected festivals). Localness-understood as the capital of relations and inside knowledge-is their best, if not only tool to compete successfully, or at least to survive the competition against huge international media conglomerates and their cinema distribution branches. At the same time, Polish distributors are aware that factors that help them in the local market (such as relationships with cinemas, media contacts, knowing the preferences of domestic audiences, expertise in creating promotional campaigns and familiarity with regulations) are also their weaknesses in foreign markets, as they are controlled by similar players there.

Traditional cinematic distributors and, indirectly, producers seem to be aware they exist in a comfortable production-distribution niche, based on the cofinancing of their projects from public funds, promotion in the international festival circuit, and the "reversed economy" of European cinema in recent decades, which is based on symbolic capital and prestige (English 2008), where symbolic values can be more important than simply the bottom line. They are even less inclined to think about exports and international expansion than some smaller VOD market entities. The cinematic distributors and the majority of the producers seem to assume, quite realistically, that the world beyond their niches is an immense ocean, and trying to cross it in their humble ships now and in the foreseeable future will lead to certain death by sinking or crashing upon the cliffs rather than the discovery of a bountiful New World.

The current growth of profits in Polish cinematic distribution is caused by the expanding traditional market. The cinematic distribution and VOD sectors in Poland will most likely be characterized by parallel development, with limited spheres of contact and overlap, aside from the selling of content to VOD services by cinematic 
distributors, while the VOD sector itself, both on the level of corporate management and content, will be characterized by an increasing level of convergence with television. ${ }^{1}$

\section{References}

English, J. (2008). The economy of prestige: Prizes, awards, and the circulation of cultural value. Cambridge: Harvard University Press.

Grece, C., \& Fontaine, G. (2017). Trends in the EU SVOD Market. Strasbourg: European Audiovisual Observatory.

Kanzler, M., \& Talavera, J. (2017). Focus 2017: World film market . Strasbourg: European Audiovisual Observatory.

Kozłowsky, K. (2018). Filmy Netflix w kinach w Polsce - są, będą, ale jakim cudem się tam znalazły? Antyweb, October 19.

Twitter. (2018). Tweet by user @ Sfilmowani. 4 October 2018, 4:31. https://twitter.com/Sfilmowani/ status/1047811558133391360. Accessed November 16, 2019.

Marcin Adamczak is Associate Professor at the Institute of Cultural Studies, Adam Mickiewicz University, Poznań and Visiting Professor at the Łód'z Film School and University, Gdańsk. He specializes in contemporary film markets, distribution and European film industries. He also worked as Director of the Cinemaforum Short Film Festival in Warsaw (2016-2018) and is cofounder of the distribution company Velvet Spoon (since 2018).

Open Access This chapter is licensed under the terms of the Creative Commons Attribution 4.0 International License (http://creativecommons.org/licenses/by/4.0/), which permits use, sharing, adaptation, distribution and reproduction in any medium or format, as long as you give appropriate credit to the original author(s) and the source, provide a link to the Creative Commons license and indicate if changes were made.

The images or other third party material in this chapter are included in the chapter's Creative Commons license, unless indicated otherwise in a credit line to the material. If material is not included in the chapter's Creative Commons license and your intended use is not permitted by statutory regulation or exceeds the permitted use, you will need to obtain permission directly from the copyright holder.

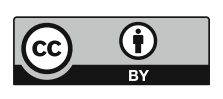

\footnotetext{
${ }^{1}$ This work was supported by the European Regional Development Fund project "Creativity and Adaptability as Conditions of the Success of Europe in an Interrelated World" (reg. no. CZ.02.1.01/0.0/0.0/16_019/0000734). This work was also supported by Ministry of Science and Higher Education through the National Program for the Development of the Humanities, module Development 2b, 2016-2019 (0135/NPRH/H2b/83/2016) and the National Science Center, Poland (UMO-2017/27/Z/HS4/00039).
} 